\title{
Formation of Droplets on Thin Film Surface in Pulsed Laser Deposition Using Metal Targets*
}

\author{
by Salim MUSTOFA**, TSUYUGUCHI Satoshi**, ARAKI Takao***, NISHIDA Minoru*** and HINO Takanori****
}

\begin{abstract}
The relationship between the morphology of $\mathrm{Au}, \mathrm{Cu}$ and $\mathrm{Ag}$ metal targets and the formation of droplets on the metal thin films was investigated using the Pulsed Laser Deposition (PLD). The metal thin films were made from the metal targets by irradiating KrF excimer laser at various laser fluences from $2.5 \mathrm{~J} / \mathrm{cm}^{2}$ to $10 \mathrm{~J} / \mathrm{cm}^{2}$ in a vacuum chamber. The surface morphology of the target after laser irradiation was observed by a Scanning Electron Microscope (SEM). It was found that spouting holes occurred on the surface of the Cu target after laser irradiation at the laser fluence of $10 \mathrm{~J} / \mathrm{cm}^{2}$. Droplets of about $1 \mu \mathrm{m}$ in diameter were found around the spouting holes. Oxygen, Phosphor and Sulphur were detected at the spouting holes from Energy Dispersive X-Ray (EDX) analyses. However, at the laser fluence of 2. $5 \mathrm{~J} / \mathrm{cm}^{2}$ spouting holes were not found. The observation on the surface of metal thin film indicates that particles of about 1 um in diameter fly out away from the target and then reach on the surface of substrate with high velocity as droplets. The same phenomenon was observed when $\mathrm{Ag}$ and $\mathrm{Au}$ targets were used. In the case where a high purity of $\mathrm{Cu}$ (111) single crystal target was used, it was obvious that the surface morphology of the target after laser irradiation would be good enough at the central zone subjected to the laser irradiation of higher laser energy than at the circumference zone.
\end{abstract}

Key Words: PLD, KrF Excimer Laser, Metal Thin Films, Droplets, Spouting Holes, Impurity, Single Crystal

\section{Introduction}

Pulsed Laser Deposition (PLD) has turned out to be the method of choice for the fabrication of high quality ceramic or metal thin films of simple and complex stoichiometry ${ }^{1)}$. The beam of an energetic pulsed excimer laser was focused onto a target. Due to the high energy density applied to the target surface, immediate evaporation - i.e. ablation - takes place. The principal advantages of PLD are considered as follows : (1) the target is ablated with the stoichiometry being conserved; and (2) the flexibility and ease of experimental setup allow to a large extent variation of the deposition parameters to find out optimal conditions. On the other hand, the presence of droplets and inhomogeneous thickness profiles over large-scale areas are the main drawbacks of $\mathrm{PLD}^{2,3)}$. Therefore, in fabricating thin films using PLD method, the droplets that exist on the surface of thin films are the main problem at the present time, which would have an influence on the final property of films. A number of papers have so far been published and many solutions have been proposed and presented concerning the elimination or reduction of droplets on the film surface ${ }^{4-8)}$, but a complete and satisfactory solution has yet to be found, especially for metals target.

It has been reported ${ }^{8)}$ that the morphology of the target surface, which becomes more and more eroded and rough with increasing of deposition time, plays an important role in determining the quantity and size of droplets deposited on the surface of the substrate. In order to investigate the main cause of droplets occurrence on the surface of thin films, in this paper, we have described the change of the target surface morphology after laser irradiation at various laser fluences and metal targets in addition to various purities of $\mathrm{Cu}$ targets. The mechanism of ablation phenomenon was also investigated.

\section{Experimental procedure}

$\mathrm{Cu}, \mathrm{Ag}$ and $\mathrm{Au}$ thin films were deposited on $\mathrm{Si}$ (100) wafers by laser ablation of commercially available $\mathrm{Cu}, \mathrm{Ag}$, high purity $\mathrm{Au}$ (99.95\% of purity) and high purity of $\mathrm{Cu}$ (111) single crystal of targets using $\mathrm{KrF}$ excimer laser. A Q-switched $\mathrm{KrF}$ excimer laser (Sumitomo Heavy Industries ; PM-888) with pulse width of $22 \mathrm{~ns}$, wavelength of $248 \mathrm{~nm}$, maximum laser energy of $900 \mathrm{~mJ}$, and maximum pulse repetition rate of $100 \mathrm{~Hz}$ was used for clarifying the mechanism of droplets formation on the surface of metal thin films. The laser beam was focused onto the metal target in a vacuum chamber under an initial pressure of $3 \mathrm{mPa}$. The angle of incidence of the laser beam was $45^{\circ}$, while the target-substrate distance was about $70 \mathrm{~mm}$. The targets were polished with diamond powder of $6 \mu \mathrm{m}$ grade as pre-treatment. Schematic illustration of the laser equipment and experimental process used in this work are shown in Fig. 1.

Two experimental conditions of deposition were used as shown in Table 1. The first experimental condition of laser irradiation was conducted at various laser fluences varying from 2.5 to 10

\footnotetext{
*Received : 2002. 5. 27

**Student Member, Graduate School of Ehime University

***Member, Faculty of Engineering, Ehime University

****Member, Dept. of Materials Science \& Engineering, Niihama National College of Technology
} 
$\mathrm{J} / \mathrm{cm}^{2}$ at 1 pulse for clarifying the initial state of laser ablation on the target. The pulse repetition was kept constant at $10 \mathrm{~Hz}$. The second experiment was carried out by varying the laser energy from 5 to $20 \mathrm{~J} / \mathrm{cm}^{2}$, under the pulse repetition rate of 10-50 $\mathrm{Hz}$ for 5000 pulses for evaluating the effect of laser fluence on droplet density. Moreover, we used the single crystal of $\mathrm{Cu}$ (111) as a laser target and irradiated for 50,000 pulses in order to exactly know the influence of impurities that may exist inside the target.

The surface morphology of a target after laser irradiation and the size of droplets were observed by a Scanning Electron Microscope (SEM). The composition of the target after laser irradiation and deposited thin films was measured by an Energy Dispersive X-Ray (EDX) analyzer.

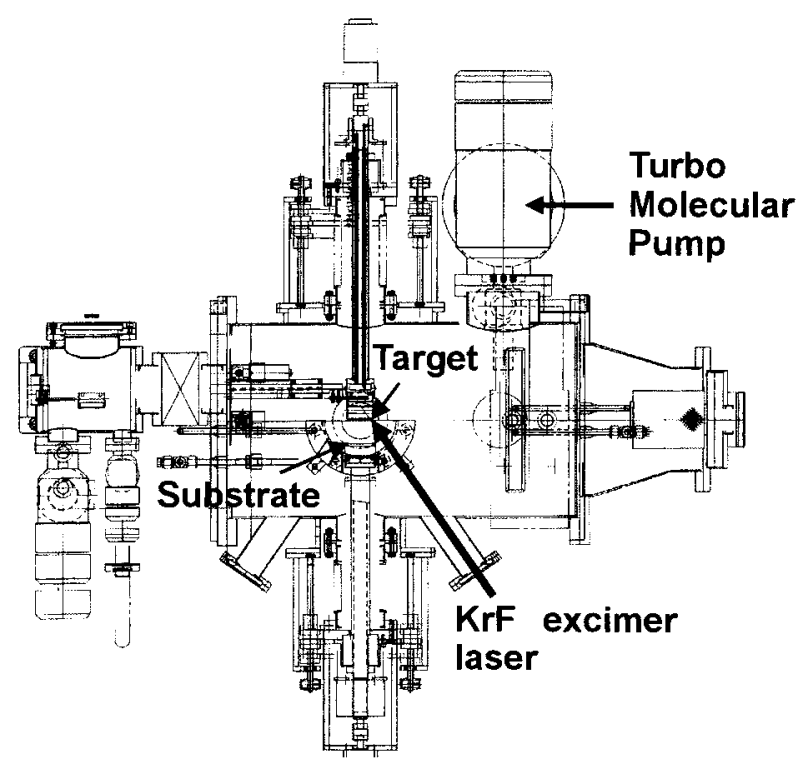

Fig. 1 Schematic illustration of laser ablation apparatus.

\section{Results and Discussion}

3.1 The effect of laser ablation in the initial state on the surface morphology of the target

Figure 2 shows the plume shape in ablation of the $\mathrm{Cu}$ target. Furthermore, to make easier the observation of plume shape, the oxygen gas pressure was set to $5 \mathrm{~Pa}$, which was higher than at the time of thin films production. From this visible photograph, the mechanism of thin film production could be observed, which included the plasma cloud; the ablated material expands into the free space and precipitates onto the substrate as a thin film.

Figure 3 shows the surface morphologies of the $\mathrm{Cu}$ target after laser irradiation at 1 pulse. At the laser fluence of $10 \mathrm{~J} / \mathrm{cm}^{2}$, the wavelike melted marks were not seen in the laser irradiation area. However, the holes (marked with a black spot) are considered to be the origin of an explosive spout existing in the target. The holes also existed on the surface of the $\mathrm{Cu}$ target even at the lowest laser fluence of $2.5 \mathrm{~J} / \mathrm{cm}^{2}$. Many holes were also observed on the surface of the $\mathrm{Au}$ and $\mathrm{Ag}$ targets by laser

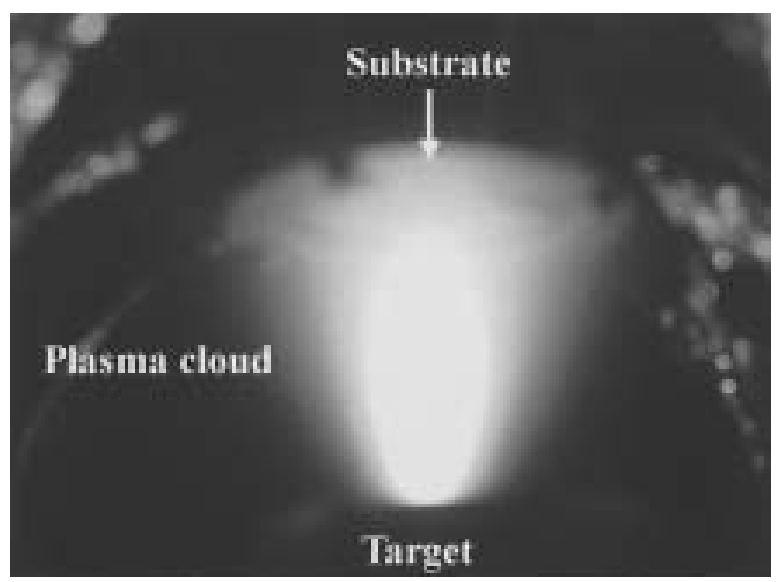

Fig. 2 The plume shape in the ablation of $\mathrm{Cu}$ target at the oxygen pressure of $5 \mathrm{~Pa}$.

Table 1 Experimental conditions of laser irradiation.

\section{Step one}

\begin{tabular}{lccc}
\hline & Step one & \multicolumn{2}{c}{ Step two } \\
\hline Main aim & $\begin{array}{c}\text { To clarify the initial state of } \\
\text { laser ablation on the target }\end{array}$ & $\begin{array}{c}\text { To evaluate the effect of laser } \\
\text { fluence on droplet density }\end{array}$ \\
\hline Pulse repetition rate $(\mathrm{Hz})$ & 10 & \multicolumn{2}{c}{10,20 and 50} \\
\hline Substrate Temperature $(K)$ & $\mathrm{R} . \mathrm{T}$. & $\mathrm{Ag}$ & $\mathrm{Cu}(111)$ \\
\hline Target & $\mathrm{Cu}, \mathrm{Au}, \mathrm{Ag}$ & $5,10,15$ and 20 & 10 \\
\hline Laser fluence $\left(\mathrm{J} / \mathrm{cm}^{2}\right)$ & $2.5-10$ & 5000 & 50,000 \\
\hline Pulse(s) & 1 & \multicolumn{2}{c}{$3 \mathrm{mPa}$} \\
\hline Atmospheric pressure & $3 \mathrm{mPa}$ & \multicolumn{3}{c}{} \\
\hline
\end{tabular}




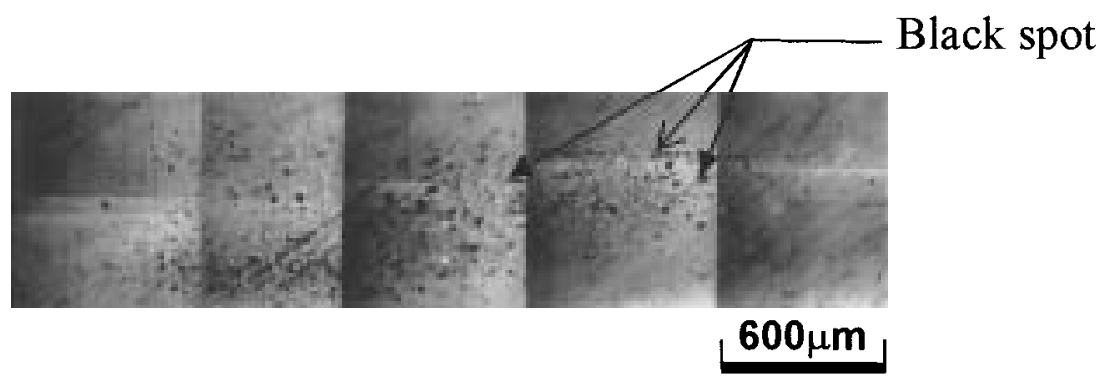

Fig. 3 Optical micrograph of the surface morphology in $\mathrm{Cu}$ target after laser irradiation at $10 \mathrm{~J} / \mathrm{cm}^{2}$ for 1 pulse.

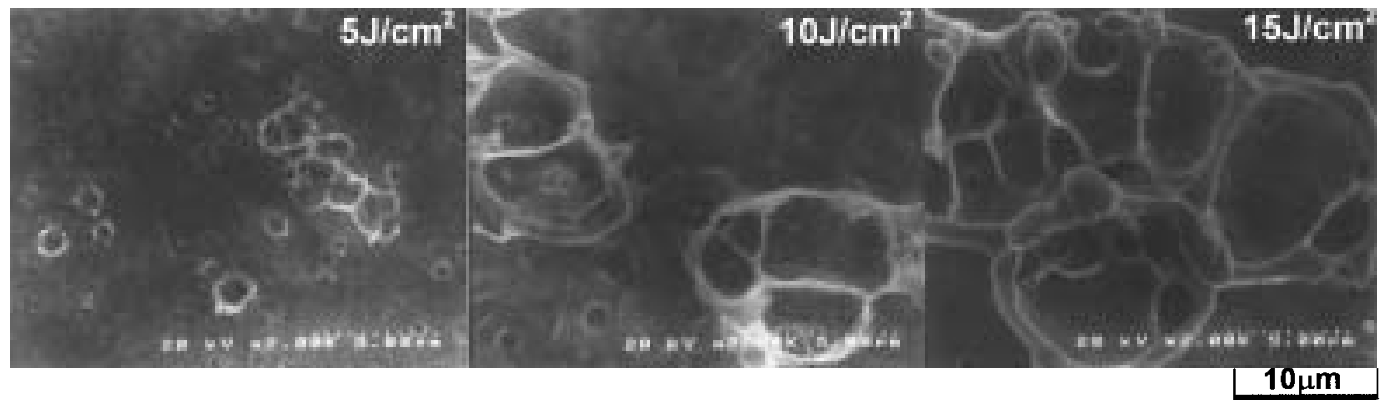

Fig. 4 SEM micrographs of the surface morphology in Ag target after laser irradiation for 1 pulse at various laser fluences.

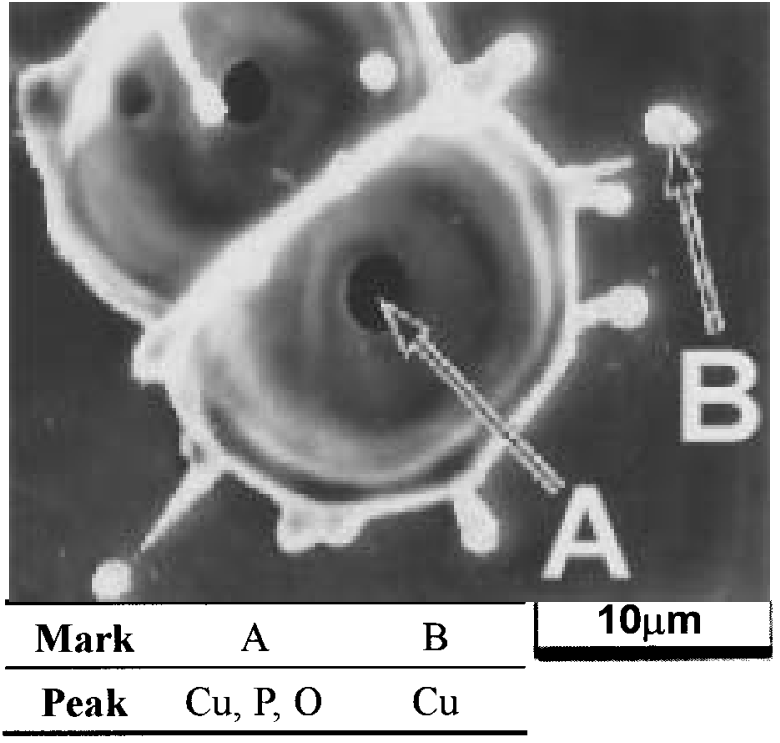

Fig. 5 SEM image and EDX spot analyses of $\mathrm{Cu}$ target surface after laser irradiation at laser fluence of $10 \mathrm{~J} / \mathrm{cm}^{2}$ for 1 pulse.

irradiation of 1 pulse.

Figure 4 shows the SEM micrographs of the Ag target surface, which was irradiated by excimer laser for 1 pulse at the laser fluence of 5,10 and $15 \mathrm{~J} / \mathrm{cm}^{2}$. The surface roughness was emphasized with the increase in laser fluence. In the laser fluence beyond $5 \mathrm{~J} / \mathrm{cm}^{2}$, the spherical particles of about several $\mu \mathrm{m}$ in diameter were cooled just before scattering directly from the spouting holes. Although the diameter of a spouting hole was about $2 \mu \mathrm{m}$ at the laser fluence of less than $4 \mathrm{~J} / \mathrm{cm}^{2}$, the diameter size increased with the increase in laser fluence. At the laser fluence of $15 \mathrm{~J} / \mathrm{cm}^{2}$, the diameter was about 9-14 $\mu \mathrm{m}$.

Figure 5 shows the SEM micrograph of spouting holes existed on the surface of the $\mathrm{Cu}$ target and the result of EDX analyses. The strong peaks of Phosphor and Oxygen were detected in the central part of the hole (mark $A$ ). In the upper heaved part (mark $B$ ), only the peak of $\mathrm{Cu}$ was detected. It is thought that Phosphor and Oxygen were detected from the surface of the $\mathrm{Cu}$ target after laser irradiation and any other impurities such as oxides served as cores. It is based on the following reason that impurities, such as Phosphor and Oxygen, are considered as a cause of droplets. It is generally said that laser beam is easy to be absorbed by nonmetallic inclusion. Therefore, it appears that a rapid rise of the laser adsorptivity in the portion of nonmetallic inclusions during laser irradiation caused a melting and gas expansion. These caused an explosive spouting from the surface of the target, and it is guessed that the spouting explosive is the factor of the spherical particle scattering.

Figure 6 shows the SEM micrographs of the surface of $\mathrm{Au}$ (upper) and Ag (lower) target, and their EDX analyses result. Also in the high purity $\mathrm{Au}$, many holes existed on the surface of the target. Peaks of Si and $\mathrm{O}$ were detected at the central part of hole (mark $D)$. In the upper heaved part (mark $C$ ), only the peak of Au was detected. In the case of the Ag target as shown in Fig. 6 (lower), the spouting holes (mark $E$ ) and the spherical particles (mark F) were observed. The peaks of $\mathrm{Ag}$ and $\mathrm{O}$ were detected at the central part (mark E), and only the peak of Ag was detected in the upper heaved part of a hole $(\operatorname{mark} F)$. Other peaks, such 
as Phosphor and $\mathrm{Si}$, were not detected in Ag. However from the result of EDX analyses, it is thought that in the Au and Ag targets, the oxides such as $\mathrm{SiO}_{2}$ and any other oxides that existed on the target surface became the cores, and caused the explosive spout.

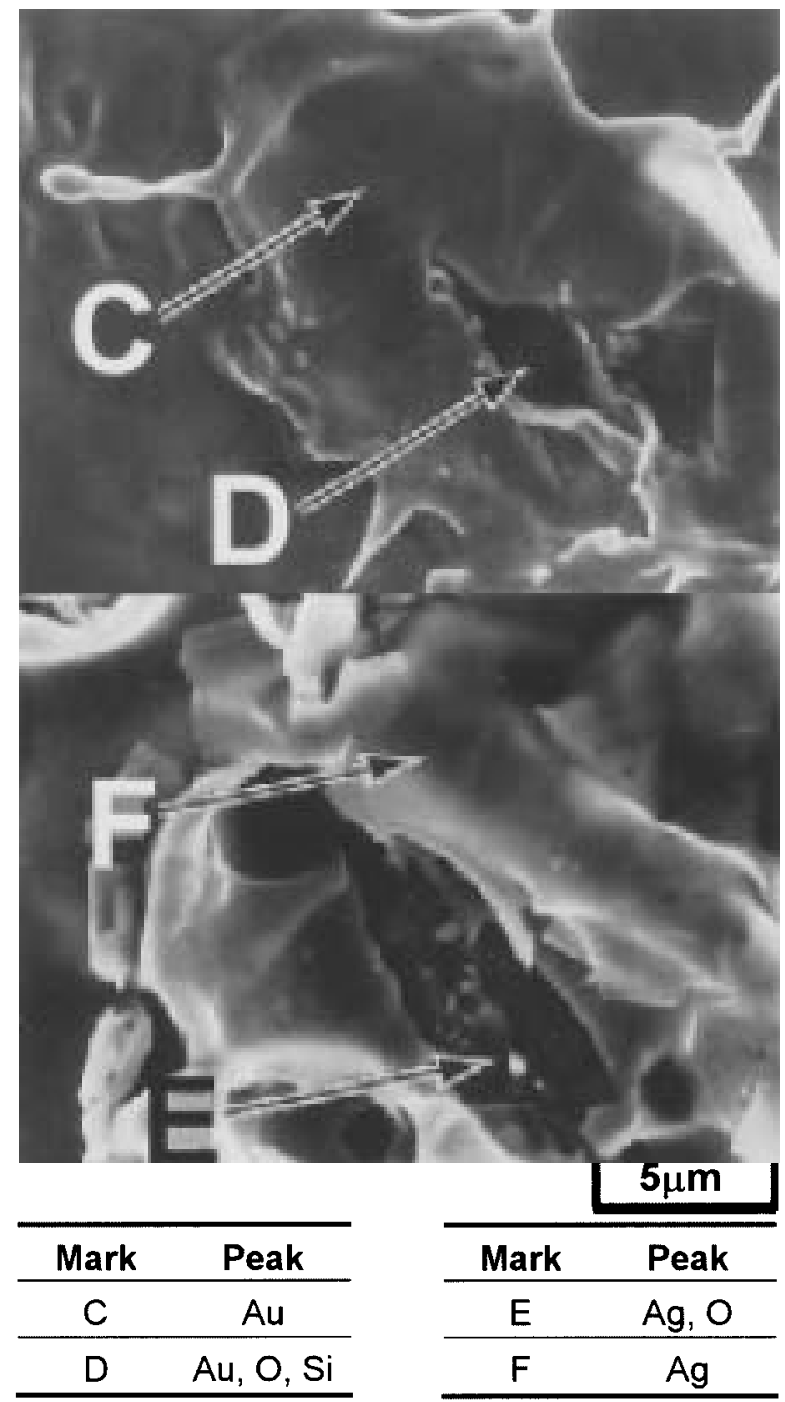

Fig. 6 SEM images and EDX spot analyses of Au (upper), and Ag (lower) target surface after laser irradiation at laser fluence of $10 \mathrm{~J} / \mathrm{cm}^{2}$ for 1 pulse.

\subsection{Effect of laser ablation on produced thin films}

Although the thin film surface was very smooth, droplets of several $\mu \mathrm{m}$ in diameter had deposited in any laser fluence. Figure 7 shows the density of droplets in a $100 \mu \mathrm{m} \times 100 \mu \mathrm{m}$ area of thin film surface.

Droplet density increased with increasing laser fluence. The density of large droplets of $2 \mu \mathrm{m}$ or more in particle diameter increased functionally as the 1 st order with laser fluence. The density of droplets of $1 \mu \mathrm{m}-2 \mu \mathrm{m}$ in particle diameter shows the maximum value in the middle, and increased abruptly above the laser fluence of $10 \mathrm{~J} / \mathrm{cm}^{2}$. The density of small droplets of $1 \mu \mathrm{m}$ or less in diameter became highest at $15 \mathrm{~J} / \mathrm{cm}^{2}$, and decreased at the laser fluence of $20 \mathrm{~J} / \mathrm{cm}^{2}$. Since the laser fluence increased, it is thought that much larger droplets of particles were dispersed. The total number of droplets increased with the rise in the laser fluence, and increased rapidly at the laser fluence of above 10 $\mathrm{J} / \mathrm{cm}^{2}$ as shown in Fig. 8. The thin film produced by a laser fluence of $4.5 \mathrm{~J} / \mathrm{cm}^{2}$ and $5 \mathrm{~J} / \mathrm{cm}^{2}$ contained few droplets, and was in a good morphology.

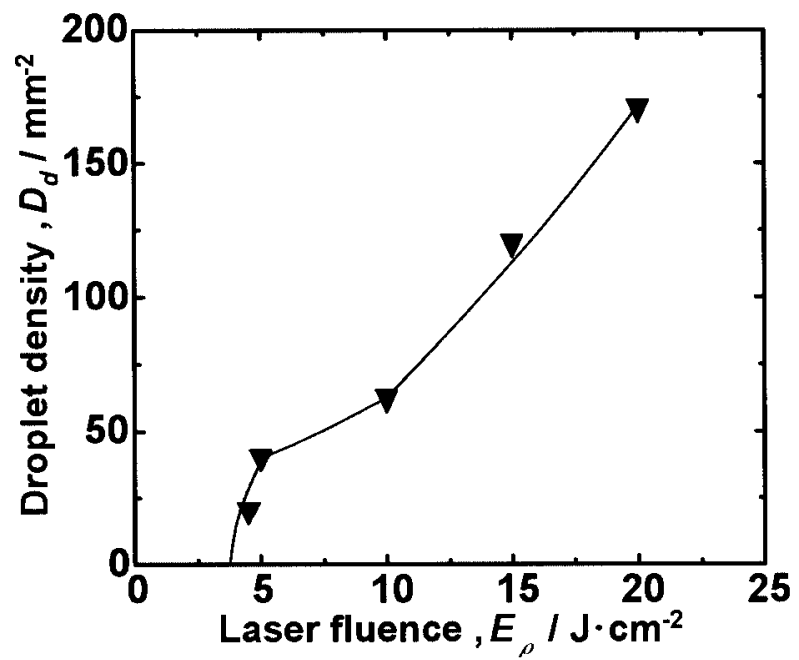

Fig. 8 Effect of laser fluence on the total number of droplets in Ag target calculated from Figure 7.
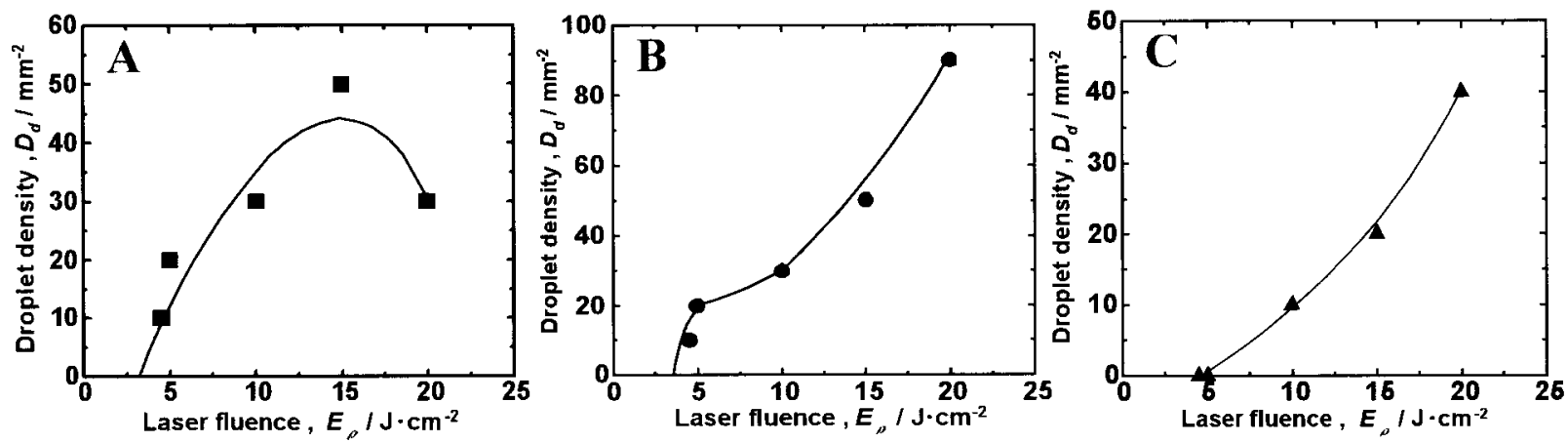

Fig. 7 Effect of laser fluence on droplets density in Ag target after laser irradiation at $10 \mathrm{~Hz}$ for 5000 pulses ; A) droplet diameter size $<1 \mu \mathrm{m}, \mathrm{B}$ ) droplet diameter size 1-2 $\mu \mathrm{m}, \mathrm{C}$ ) droplet diameter size $>2 \mu \mathrm{m}$. 


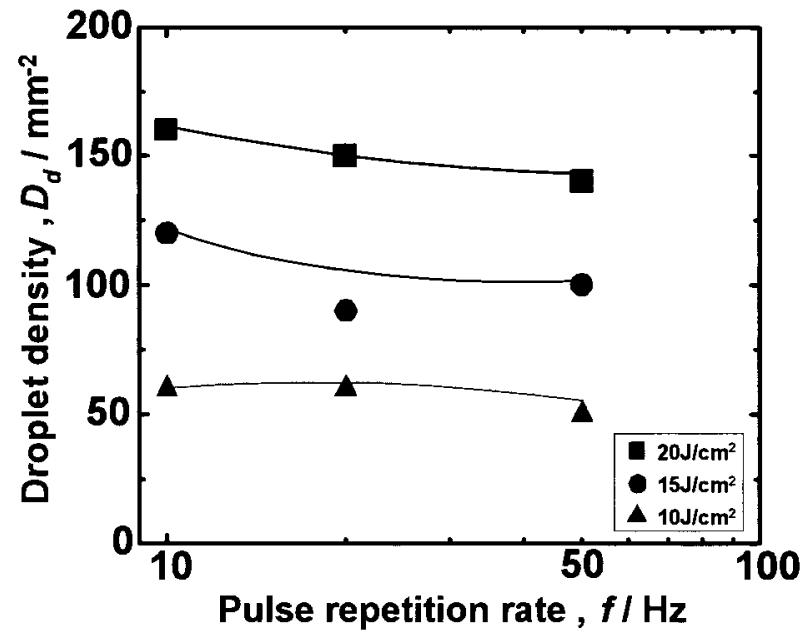

Fig. 9 Effect of pulse repetition rate on the total number of droplets in Ag target after laser irradiation for 5000 pulses. droplets, which were dispersed directly from the melting part. To make a thin film with good characteristic, as described in the part of introduction, it is necessary to eliminate the droplets from depositing on the surface of thin film. From the result of this work, it could be said that the purity of the target influences the formation of the droplets. Therefore it is necessary to form a target of high purity. For clarifying the influence of target purity, a single crystal of $\mathrm{Cu}$ (111) from $4 \mathrm{~N} \mathrm{Cu}$ was made and used as a target for laser ablation. Figure 12 shows the surface of $\mathrm{Cu}$ (111) single crystal target after laser irradiation for 50,000 pulses, and Fig. 13 shows SEM enlarged photos of the circumference zone (mark $A$ ) and the central zone (mark $B$ ) observed by SEM. At the circumference zone of laser irradiation, the particle that can become a droplet was recognized. On the other hand, at the central zone of laser irradiation, the particle that can become a

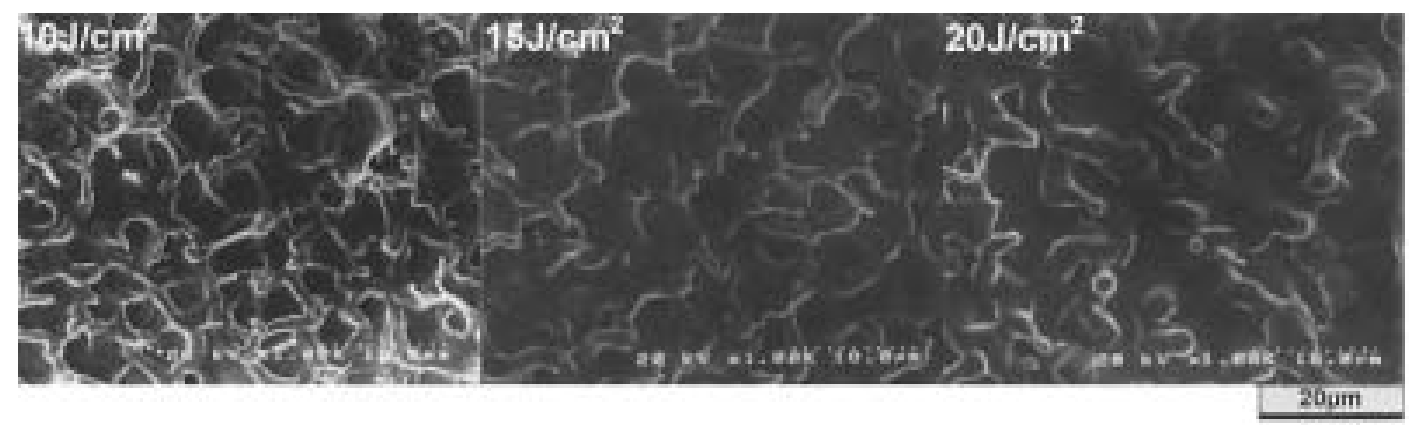

Fig. 10 SEM micrographs of the surface morphology of Ag target after laser irradiation at $10 \mathrm{~Hz}$ under various laser fluences for 5000 pulses.

Figure 9 shows the influence of pulse repetition rate on the droplet density. In this experiment, the total number of droplets did not receive an influence in the pulse repetition rate, but showed almost fixed value in all laser fluences.

Figure 10 shows the surface morphology of the Ag target after laser irradiation at the laser fluence of 10,15 and $20 \mathrm{~J} / \mathrm{cm}^{2}$ for 5000 pulses and at a pulse repetition speed of $10 \mathrm{~Hz}$. The central zone of laser irradiation has the form of wavelike surface ups and downs, and the droplets of several $\mu \mathrm{m}$ in particle diameter existed in the convex part. The surface of the target after irradiation at $20 \mathrm{~J} / \mathrm{cm}^{2}$ became rough in comparison with other conditions. When a laser beam was shot on to the target at a very high laser fluence $\left(20 \mathrm{~J} / \mathrm{cm}^{2}\right)$ the melting depth became deeper. This is considered to be the cause of the formation of many droplets with a large diameter rather than small droplets. Furthermore, this SEM observation result was in agreement with the relationship of the total number of droplets and laser fluence as shown in Fig. 8, which gave a result that the number of droplets increased with increasing laser fluence.

Since the spherical particles seen at the $\mathrm{Cu}$ target also deposited to the thin film surface as shown in Fig. 11, they were regarded as droplet was not found. Zone B showed the good surface form. From these results, it is thought that droplets are generated from the circumference zone of laser irradiation.

The energy distribution of the excimer laser is a Gaussian distribution. When a laser beam irradiated to the target, the energy at the circumference zone of the laser beam is lower than the central zone. Consequently, as shown in Fig. 13, the melting

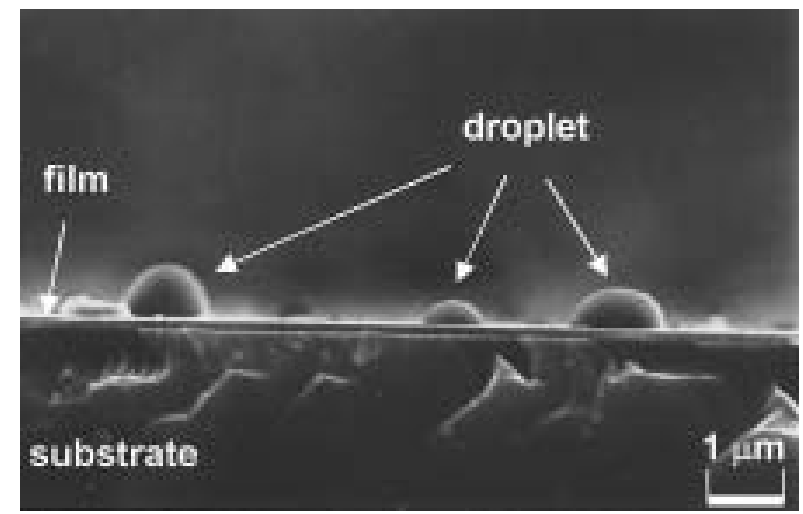

Fig. 11 SEM micrograph of droplets deposited to the surface of $\mathrm{Cu}$ thin film. 


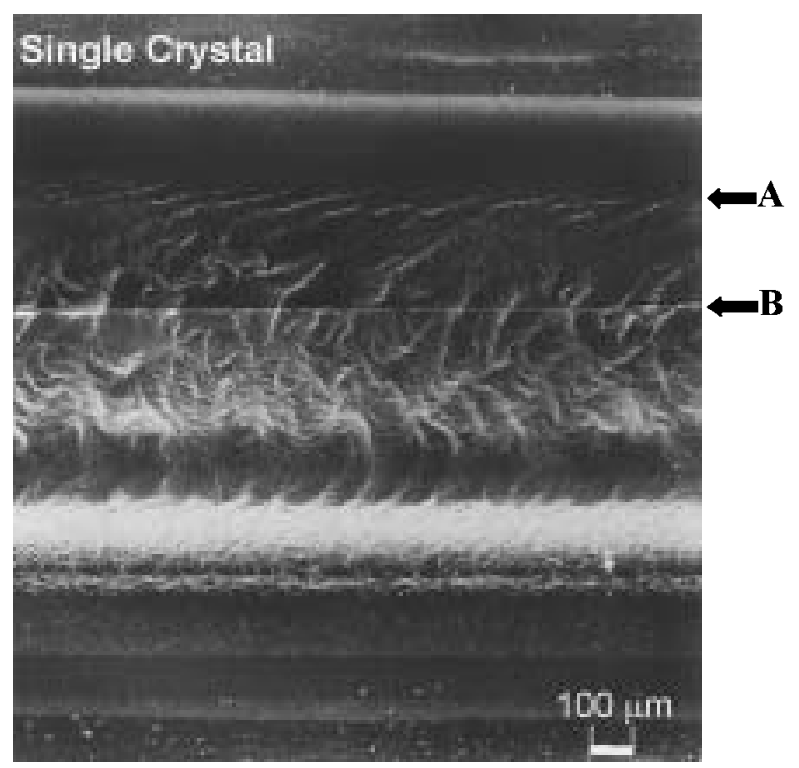

Fig. 12 Optical micrograph of the surface of the $\mathrm{Cu}$ (111) target after laser irradiation at $10 \mathrm{~J} / \mathrm{cm}^{2}$ for 50000 pulses. and nonmetallic inclusion that existed on the surface of the target influenced the droplets formation greatly.

(2)The target after 5000 pulse laser irradiation was accompanied by melting, and the spherical particles seen on the target surface dispersed directly from the melting part of the target.

(3)Although the number of droplets seen on the thin film surface increased with a rise in laser fluence, it did not depend on the pulse repetition rate.

(4)The use of the high purity and crystallized target subjected to the central zone of a laser beam during laser ablation could suppress the deposition of droplets.

\section{Acknowledgement}

This study was supported by Industrial Technology Research Grant Program in 01A25014a from New Energy and Industrial Technology Development Organization (NEDO) of Japan.

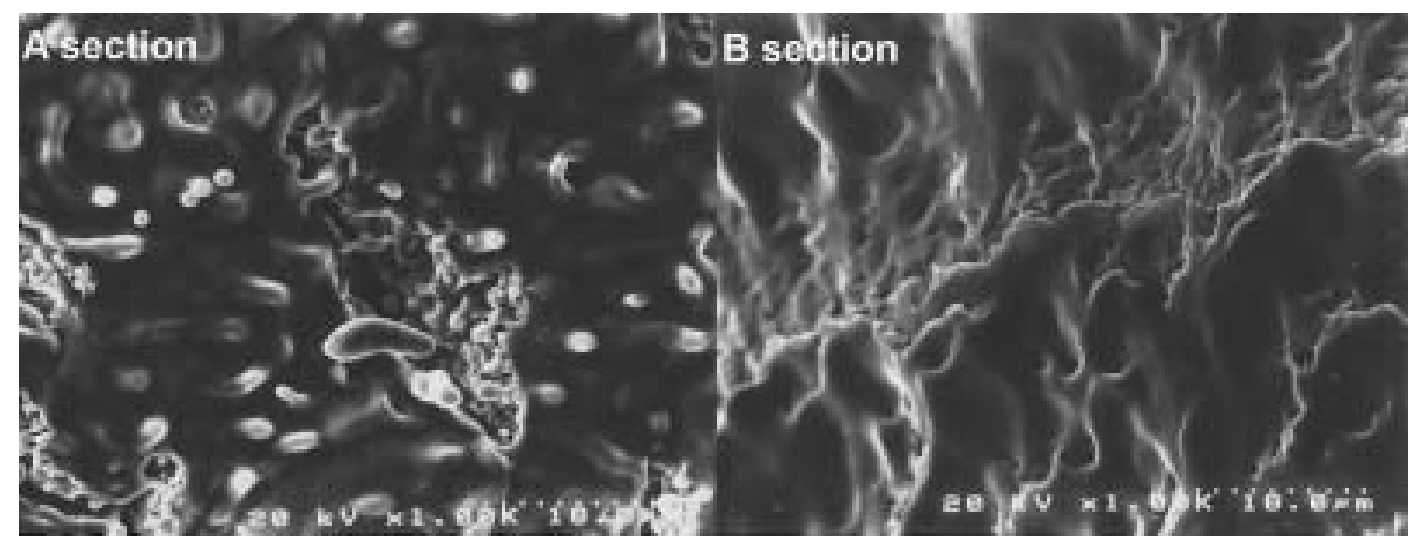

Fig. 13 Enlargement of A and B zone shown in Figure 12 of the $\mathrm{Cu}(111)$ target surface after laser irradiation at $10 \mathrm{~J} / \mathrm{cm}^{2}$ for 50000 pulses observed by SEM.

wavelike traces and the particles that can become droplets were seen at the circumference zone of laser irradiation because of its low energy. However, the wavelike traces and the particles were not seen at the central zone of laser irradiation. Therefore, a good thin film could be obtained by cutting the circumference zone of the laser beam which cause the droplets formation, and only by using the central zone of laser beam during laser ablation.

\section{Conclusions}

The laser ablation mechanism could be divided into two states ; the initial state which does not include heat influence nor the state where heat influence exists. From these points of view and the results of the experiments, the following conclusions are obtained. (1)In one pulse in which heat influence hardly existed, the oxide

\section{References}

1) D.B. Crisey and G.H. Hubler (Eds.), Pulsed Laser Deposition of Thin Films, Wiley, NY, 1997.

2) J.C. Miller and D.B. Geohegan : Laser Ablation Mechanism and Applications, AIP, New York (1994).

3) T. Szorenyi and J.M. Ballesteros : Applied Surface Science, 327 (1997) 109

4) Rebouillat, J.P., B. Michelutti, Y. Souche, J.P. Gavigan, D. Givord and A. Lienard : Mater. Res. Soc. Proc. 151 (1989) 259.

5) Gaponov, S.V., A.A. Gudkov, B.M. Luskin and N.N. Salashchenko : Sov. Phys. Tech. Phys., 26 (1981) 598.

6) Gaponov, S.V., S.A. Gusev, B.M. Luskin and N.N. Salashchenko : Sov. Phys. Tech. Phys., 38 (1981) 7.

7) Barr, W.P., J. Phys., E2 (1969) 2.

8) E. van de Riet, C.J. Nillesen and J. Dieleman : J. Appl. Phys., 74 (1993) 2008 